\title{
Transition Experiments on Blunt Bodies with Isolated Roughness Elements in Hypersonic Free Flight
}

\author{
D.C. Reda ${ }^{*}$ and M.C. Wilder ${ }^{\dagger}$ \\ NASA-Ames Research Center, Moffett Field, CA 94035-1000 \\ and \\ D.K. Prabhu ${ }^{*}$ \\ ELORET Corporation, Sunnyvale, CA 94086-7607
}

\begin{abstract}
Smooth titanium hemispheres with isolated three-dimensional (3D) surface roughness elements were flown in the NASA Ames hypersonic ballistic range through quiescent $\mathrm{CO}_{2}$ and air environments. Global surface intensity (temperature) distributions were optically measured and thermal wakes behind individual roughness elements were analyzed to define tripping effectiveness. Real-gas Navier-Stokes calculations of model flowfields, including laminar boundary layer development in these flowfields, were conducted to predict key dimensionless parameters used to correlate transition on blunt bodies in hypersonic flow. For isolated roughness elements totally immersed within the laminar boundary layer, critical roughness Reynolds numbers for flights in air were found to be higher than those measured for flights in $\mathrm{CO}_{2}$, i.e., it was easier to trip the $\mathrm{CO}_{2}$ boundary layer to turbulence. Tripping effectiveness was found to be dependent on trip location within the subsonic region of the blunt body flowfield, with effective tripping being most difficult to achieve for elements positioned closest to the stagnation point. Direct comparisons of critical roughness Reynolds numbers for 3D isolated versus 3D distributed roughness elements for flights in air showed that distributed roughness patterns were significantly more effective at tripping the blunt body laminar boundary layer to turbulence.
\end{abstract}

\section{Nomenclature}

$\mathrm{k}=$ roughness height

$\mathrm{M} \quad=$ Mach number

$\mathrm{P} \quad=$ static pressure

$\mathrm{Re}_{\mathrm{kk}}=$ roughness Reynolds number, $\rho_{\mathrm{k}} \mathrm{u}_{\mathrm{k}} \mathrm{k} / \mu_{\mathrm{w}}$

$\operatorname{Re}_{\theta}=$ momentum thickness Reynolds number, $\rho_{\mathrm{e}} \mathrm{u}_{\mathrm{e}} \theta / \mu_{\mathrm{e}}$

$\mathrm{T}=$ temperature

$\mathrm{u} \quad=$ velocity

$\mathrm{V}_{\infty} \quad=$ model velocity at measurement station

$\delta=\quad$ laminar boundary layer thickness

$\theta \quad=$ laminar boundary layer momentum thickness

$\mu \quad=$ fluid viscosity

$\rho \quad=$ fluid density

$\phi \quad=$ azimuthal angle measured along hemisphere surface from stagnation point

subscripts

e $\quad=$ at boundary layer edge

$\mathrm{k} \quad=$ at roughness height

* Senior Research Scientist, Aerothermodynamics Branch, MS 230-2; Fellow, AIAA.

$\dagger$ Aerospace Engineer, Aerothermodynamics Branch, MS 230-2; Associate Fellow, AIAA.

$\ddagger$ Principal Research Scientist, ELORET Corporation, Sunnyvale, CA; Associate Fellow, AIAA.

1

American Institute of Aeronautics and Astronautics 


$\begin{array}{ll}\text { stag } & =\text { at stagnation point } \\ \mathrm{TR} & =\text { at transition } \\ \mathrm{W} & =\text { at wall conditions } \\ \infty & =\text { freestream }\end{array}$

\section{Problem Statement}

MODELING of roughness-dominated transition to turbulence is an important design issue for ablating (single use) and non-ablating (reusable) thermal protection systems (TPS). Two categories of surface roughness are associated with each type of TPS: distributed surface roughness and isolated surface roughness.

Ablating TPS, for single-use planetary-entry and Earth-return missions, first experience recession under highaltitude, low-Reynolds-number conditions. Such laminar-flow ablation causes the formation of a distributed surface microroughness pattern characteristic of the TPS material composition and fabrication process. Once formed, these distributed surface roughness elements create disturbances within the laminar boundary layer flowing over the surface. As altitude decreases, Reynolds number increases, and flowfield conditions capable of amplifying these roughness-induced perturbations are eventually achieved, that is, transition onset occurs. Boundary-layer transition to turbulence results in more severe heat transfer rates and accelerated surface recession. Ablating TPS thus can potentially encounter failure mechanisms associated with exceeding bond-line temperature limits, burn through, or thermo-structural break up.

Ablating and non-ablating TPS comprised of many tiles or panels also have distributed surface roughness patterns associated with the nominal (within design specifications) tile misalignments that inherently occur as the heat shield is assembled from discrete pieces. A classic example, for non-ablating TPS, is found on the windward surface of the Space Shuttle Orbiter.

Distributed surface roughness patterns generally cause transition to turbulence to occur simultaneously over large surface-area portions of the TPS, the boundary between the laminar-flow region and the turbulent-flow region being referred to as the transition front.

Isolated roughness elements, on the other hand, represent localized disturbance sources within the laminar boundary layer. Transition to turbulence behind any such discrete element occurs in a narrow, flow-aligned zone, its lateral extent usually spreading at shallow angles as the turbulent zone convects downstream.

Isolated roughness elements on ablating and re-usable TPS are generally associated with design and/or assembly issues. Heat shields comprised of discrete segments or "tiles" have two potential sources of isolated roughness elements: (1) localized tile surface misalignments outside of design specifications; and (2) the potential protrusion of gap-filler material placed between the tiles. Finally, all entry capsules are mated to launch vehicles, and a design feature must be employed to isolate the TPS material from launch accelerations and directly-applied compressive loads. This can be accomplished by inserting "compression pads" of high-strength material at discrete locations within the TPS to allow for direct contact with adjacent load-bearing components. If these compression pads initially protrude above the TPS surface, or, due to differential ablation, protrude later in the entry trajectory, then the net result would be the formation of isolated surface roughness elements.

Designers of ablating and non-ablating TPS require physics-based criteria that allow for the accurate modeling of transition to turbulence as caused by distributed roughness patterns and isolated roughness elements.

\section{Review of Previous Research}

The 2002 review article by Reda $^{1}$ serves as the starting point for the present discussion. The primary conclusion of this earlier review of published roughness-dominated transition correlations for blunt bodies, attachment lines and windward surfaces of lifting-entry vehicles was that all such correlations could be recast into, and be well modeled by, the critical roughness Reynolds number concept.

The concept of a critical roughness Reynolds number for transition is attributed to Schiller ${ }^{2}$, who hypothesized that, at some critical value, vortices would be shed from the top of the roughness element(s), causing an abrupt breakdown to turbulence. The critical Reynolds number was based on smooth-wall laminar boundary-layer conditions at the roughness height, and the length scale was the roughness height. Citations given in Reference 1 document the evolution of this concept from its inception up to 2002 .

In 2004, Reshotko and Tumin ${ }^{3}$ published the first-ever mathematical model for distributed-roughness-induced transition on blunt bodies in hypersonic flow. Their computational approach was based on spatial transient growth theory, pioneered by them, and predicted trends were found to be in general agreement with the critical roughness Reynolds number correlating approach. Comments on the databases used to "calibrate" their model were offered by Reda ${ }^{4}$. 
In 2006, Schneider ${ }^{5}$ published a review article concerning transition on blunt reentry capsules and planetary probes. Issues related to the impact of transition on both TPS and afterbody flowfields were discussed. In this time frame, NASA interest was undergoing a dramatic shift away from lifting entry vehicles, such as the Space Shuttle Orbiter, and was beginning to concentrate, once again, on blunt capsules such as the Crew Exploration Vehicle (CEV) for future manned missions.

Early 2008 saw the publication of a special issue of the Journal of Spacecraft and Rockets dedicated, in large part, to transition on hypersonic vehicles. References 6 through 9, taken from this source, are most relevant to the present discussion.

In summary of the current state-of-the-art, the distributed-roughness-induced transition correlation of Reda, based on quiescent, real-gas, hypersonic experiments conducted in ballistic ranges, offers a design tool for TPS surface-roughness requirements on blunt body geometries. A similar design correlation for isolated surface roughness elements has been put forward by Berry and Horvath ${ }^{9}$. Amar, et a1. ${ }^{10}$, and Berger ${ }^{11}$ expanded the available isolated-roughness database to include the CEV blunt capsule geometry. However, the published wind-tunnel databases of References 9, 10, and 11 have yet to be analyzed within the critical roughness Reynolds number framework.

The objective of the present research was thus to acquire and analyze a new database for the influence of isolated roughness elements on blunt body transition using quiescent, real-gas, ballistic-range testing methodologies ${ }^{12}$.

\section{Experimental Approach}

The experiments were performed in the Hypervelocity Free Flight Aerodynamic Facility, part of the ballistic range complex at NASA's Ames Research Center. The ballistic range, shown in Figure 1, employs a two-stage light-gas gun to launch individual models on trajectories through a controlled-atmosphere test section. The largest gun has an inner diameter of $38.1 \mathrm{~mm}(1.5 \mathrm{in})$, and the test section is approximately $1 \mathrm{~m}$ across and $23 \mathrm{~m}$ long, measured from the first optical measurement station to the last. The models are in flight for an additional $10 \mathrm{~m}$ from the exit of the gun barrel to the first optical measurement station, during which time the launch sabot is separated from the model and trapped in the receiver tank. There are 16 optical measurement stations, spaced $1.524 \mathrm{~m} \mathrm{(5 \textrm {ft } )}$ apart, along the length of the test section. Each station is equipped with orthogonal-viewing parallel-light shadowgraph cameras and high-speed timers for recording the flight trajectories. Figure 2 shows a shadowgraph picture of a model in hypersonic free flight. Pitch and yaw angles were measured from orthogonal-view photographs taken at multiple stations along each range trajectory and were generally less than a few degrees.

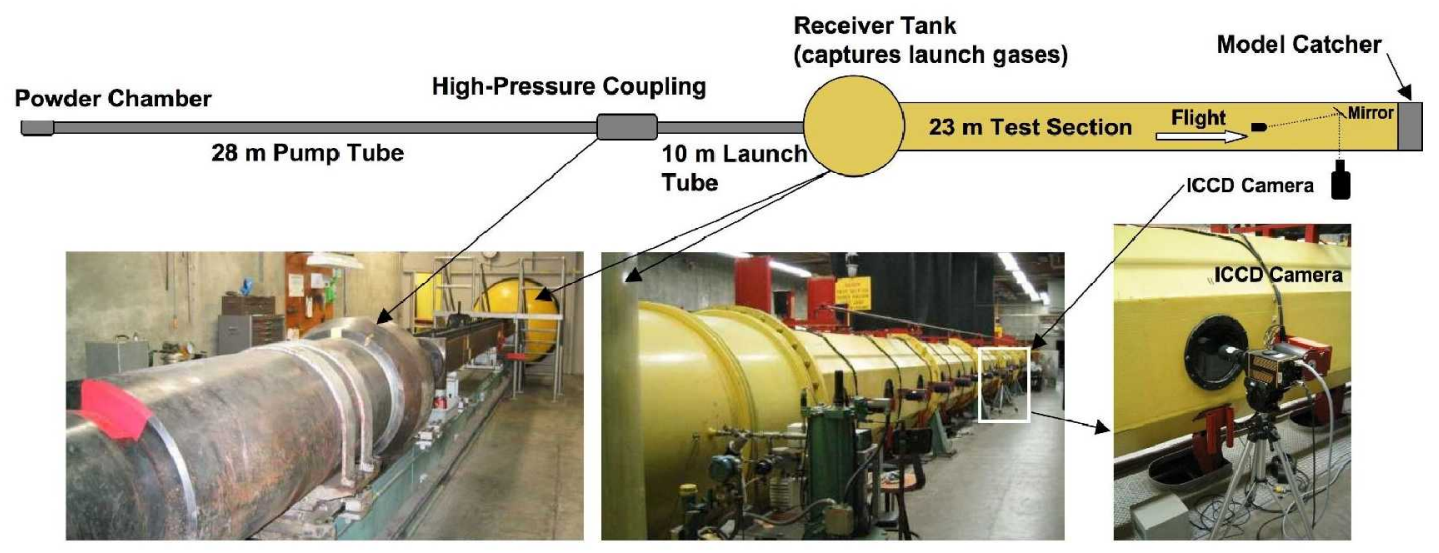

Figure 1. The NASA Ames free flight ballistic range.

Figure 3 shows a photograph of a hemispherical model, and its launch sabot, used in the present experiments. The hemispheres were made from commercially available titanium alloy (Ti-6Al-4V) ball bearings with a diameter of $2.86 \mathrm{~cm}$ (1.125 in.), which were cut in half using an electrical discharge machining (EDM) wire. The arithmetical average surface roughness was $0.2 \mu \mathrm{m}$ (grade 200 balls, as defined by the Anti Friction Bearing Manufacturers Association (AFBMA) standards), giving an aerodynamically smooth surface finish. Isolated, disk-like surface roughness elements were created by drilling holes perpendicular to the model surface at parametrically varied locations of $10^{\circ}, 20^{\circ}$ and $30^{\circ}$ of arc length from the stagnation point, then press fitting cylindrical silicon carbide pins 


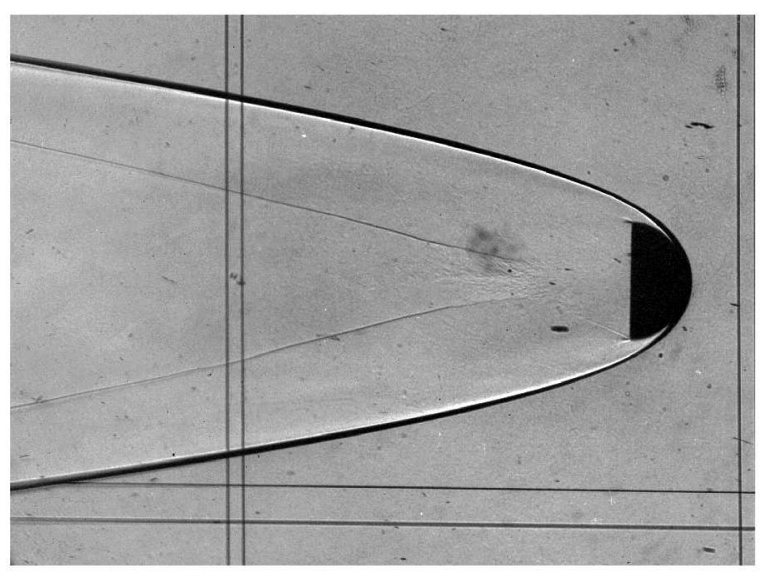

Figure 2. Shadowgraph of model in hypersonic free flight in $\mathrm{CO}_{2}, \mathrm{~V}_{\infty}=4 \mathrm{~km} / \mathrm{s}, P_{\infty}=0.2 \mathrm{~atm}$.

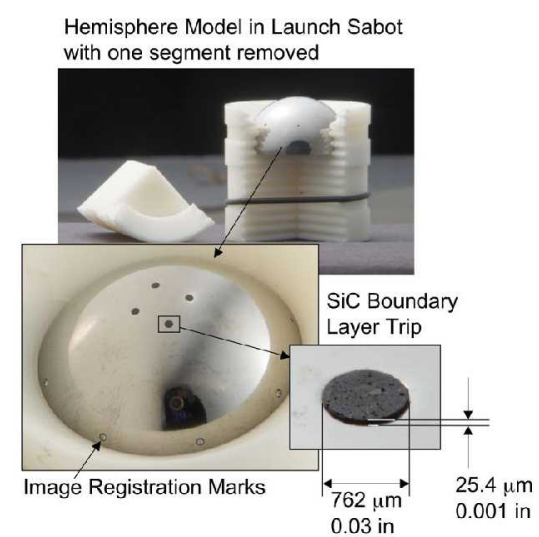

Figure 3. Titanium hemisphere model with $\mathrm{SiC}$ boundary-layer trips located 10 degrees from the stagnation point, shown in launch sabot with one segment removed.

of diameter $762 \mu \mathrm{m}$ (0.030 in.) into each hole, leaving exposed heights that were systematically varied to cover a wide range of $\mathrm{Re}_{\mathrm{kk}}$ values. Four such pins were located on each model, all at the same arc length from the stagnation point, and always separated by $90^{\circ}$ circumferentially. Roughness element heights were measured using greatly magnified silhouette images generated with an optical comparator.

For these experiments, six of the optical measurement stations were equipped with high-speed thermal imaging cameras to record the instantaneous global surface intensity distributions on the models. Three stations employed intensified CCD (ICCD) cameras sensitive to the visible wavelengths of light, and three employed infrared cameras sensitive to the 3-5 $\mu \mathrm{m}$ infrared band. The cameras were located outside the test section, and viewed the models off a first-surface plane mirror placed inside the test section, just off the line of flight, as illustrated schematically in Fig. 1. An example ICCD image is shown in Fig. 4a. The luminous wake of the model can be seen in this image. The shock-layer gases of the bow shock also radiate intensely in the visible wavelengths for the conditions of these experiments, and have the potential to bias the surface temperature measurements. A localized plume of helium was created to temporarily quench this gas-cap radiation at each ICCD imaging station, as discussed in Ref. 12. The model was in the helium less than $0.5 \%$ of the total flight time, thus its effect on the integrated

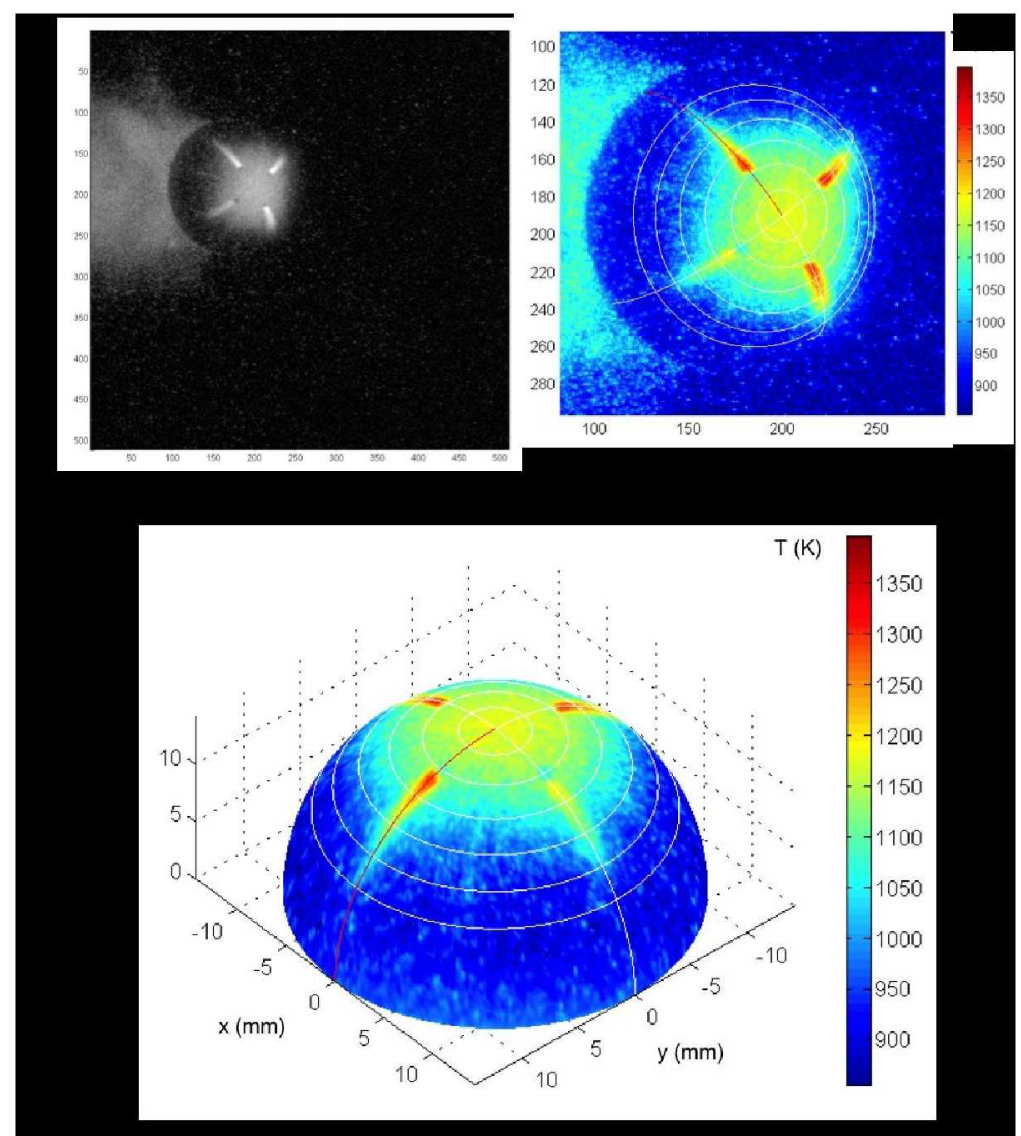

Figure 4. Example thermal image of hemisphere in flight through $\mathrm{CO}_{2}, \mathrm{~V}_{\infty}=4.0 \mathrm{~km} / \mathrm{s}, \mathrm{P}_{\infty}=0.2 \mathrm{~atm}$, with trips at $\phi=20^{\circ}$ : (a) global surface intensity distribution; (b) global surface temperature distribution with coordinate grid mapping; (c) temperature image after resection to $3 \mathrm{D}$ coordinate grid.

4

American Institute of Aeronautics and Astronautics 
convective heating over the entire trajectory was minimal. There is no appreciable gas-cap radiation in a narrow band around $4 \mu \mathrm{m}$. A notch filter at $4 \mu \mathrm{m} \pm 0.15 \mu \mathrm{m}$ was used with the mid-wave infrared waveband, so no helium plume was required for those cameras. Only the data obtained with the ICCD cameras is reported here.

Camera calibration procedures outlined in Refs. 12 and 13 were employed to convert these images to global surface temperature images (see Fig. 4b), and finally, to 3D surface temperature maps, as shown in Fig. 4c. The response of each camera was calibrated against a NIST-traceable blackbody standard by imaging the blackbody source on an optical path equivalent to that of the ballistic-range tests. For typical camera parameters used (intensifier gain and the lens aperture), the standard deviation of temperature measurements for temperatures above $900 \mathrm{~K}$ was $\pm 6 \mathrm{~K}$, both for pixel-to-pixel variations within an image of a uniform source, and image-to-image variations for a given pixel. Camera parameters were adjusted so that the peak expected temperature for a shot condition would result in as intense an image as possible without saturating the sensors. As a result, the minimum detectable temperature was typically around $950 \mathrm{~K}$ with the ICCD cameras. All images were recorded with a $0.5 \mu \mathrm{s}$ exposure time.

Both air and $\mathrm{CO}_{2}$ were employed as test gases. Freestream pressure levels were varied from $0.15 \mathrm{~atm}$ to $0.35 \mathrm{~atm}$ and freestream temperature of the quiescent test gas was at room temperature ranging from $292 \mathrm{~K}$ to $298 \mathrm{~K}$. Model/sabot packages were launched from a two-stage light gas gun at a nominal muzzle velocity of $4.5 \mathrm{~km} / \mathrm{s}$, yielding freestream velocities of order $4 \mathrm{~km} / \mathrm{s}$ at mid-range locations. Corresponding nominal freestream Mach numbers were 12 for air and 15 for $\mathrm{CO}_{2}$. The majority of the experiments were performed at a freestream pressure level of $0.2 \mathrm{~atm}$.

Laminar boundary larger development around the hemispherical model was computed for each test case using the data-parallel line-relaxation (DPLR) code of Ref. 14 (see discussions in Ref. 8). Results of these real-gas NavierStokes calculations were combined with measured trip heights and trip locations to define roughness Reynolds numbers $\left(\mathrm{Re}_{\mathrm{kk}}\right.$ values), which ranged from order 300 to order 3000 in the present experiments. The ratio of roughness height $\mathrm{k}$ to boundary layer thickness $\delta$ was always set to be less than one. Recall that the critical roughness Reynolds number value for distributed roughness on a hemispherical body for hypersonic flight through air is $\operatorname{Re}_{\mathrm{kk}, \mathrm{TR}}=250$ (Ref. 8).

\section{Effective Tripping (Transition) Criterion}

It was required that a single, consistent criterion be identified and applied to each trip in each experiment in order to define whether or not an individual isolated roughness element was "effective" at tripping the laminar boundary layer to turbulence. The basic measurement in all these experiments was the global surface temperature distribution, hence the "tripping effectiveness" criterion was based on these recorded observations (see Fig. 5). Data are presented in a non-dimensional form, using the measured stagnation point temperature for each shot to normalize shot-to-shot differences in freestream pressure and velocity.

Each surface temperature distribution measured along a roughness element wake centerline was compared to a composite of undisturbed laminar streamwise distributions measured at circumferential angles taken between pin locations on the smooth-wall segments of the hemisphere. The smooth-wall, non-dimensional profiles shown in Fig. 5 and subsequent figures, are profiles averaged over many shots. The error bars represent the root-sum-square of the standard deviation of the mean profile, and the calibration uncertainty of $\pm 6 \mathrm{~K}$. Error bars are not shown on the trip wake profiles to avoid clutter, but are of similar magnitude. At low $\mathbf{R e}_{\mathrm{kk}}$ values, surface temperature perturbations behind the trip were minimal, quickly returning to laminar levels (see curve (a), Fig. 5); at intermediate $\mathrm{Re}_{\mathrm{kk}}$ values (curve (b),

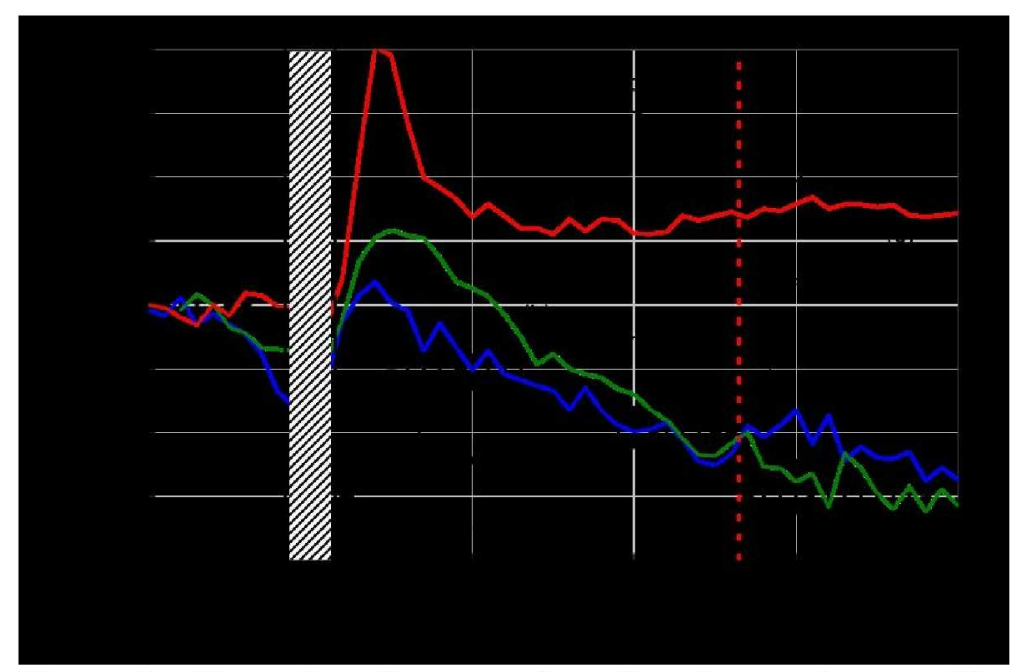

Figure 5. Examples of measured surface temperature profiles along roughness element wake centerlines for tests in $\mathrm{CO}_{2}$ : (a) $\mathrm{k} / \delta=0.6, \operatorname{Re}_{\mathrm{kk}}=603, \mathrm{P}_{\infty}=0.2 \mathrm{~atm}$; (b) $\mathrm{k} / \delta=0.78, \mathrm{Re}_{\mathrm{kk}}=779$, $P_{\infty}=0.2 \mathrm{~atm} ;$ (c) $\mathrm{k} / \delta=0.82, \operatorname{Re}_{\mathrm{kk}}=982, P_{\infty}=0.3 \mathrm{~atm}$. 
Fig. 5), an abrupt surface temperature rise was seen in the trip near wake region, but this disturbance also decayed back to the local undisturbed/laminar level as the mean flow expanded around the hemispherical model; at higher $\mathrm{Re}_{\mathrm{kk}}$ values (curve (c), Fig. 5), an abrupt surface temperature rise in the trip near wake region was also seen, but in such "effective tripping" cases, surface temperature levels remained above the composite laminar curve to well beyond the sonic line location.

Wakes of such effective isolated roughness elements are clearly turbulent in nature, although the wake may not produce heat transfer rates equivalent to those of a fully-developed turbulent flow. Comparisons with predicted heat fluxes (or surface temperatures) were not employed in the present study. In certain testing applications, a spanwise array of isolated roughness elements is sometimes used to trip the approaching laminar boundary layer to a "fullydeveloped" turbulent state. Such a response is generally not achieved until wakes of the individual roughness elements "merge" at some finite distance downstream of the trip array ${ }^{10,11}$, and may depend on other factors, such as freestream Reynolds number.

\section{Effective Tripping Results}

\section{A. $\mathrm{CO}_{2}$ Data}

Figure 6 shows a composite of selected trip thermal wakes and wake centerline axial cuts taken from the $\mathrm{CO}_{2}$ experiments. Parametric values of trip angular location are listed at the top of each column. The roughness Reynolds number value is listed at the left hand edge of each image, and the magnitude of this critical parameter increases, top to bottom, in each column. As can be seen for each trip location, systematic increases in the roughness Reynolds number resulted in stronger and more enduring thermal perturbations in the roughness element wake. Employing the tripping effectiveness criterion outlined in Fig. 5, the critical value of $\mathrm{Re}_{\mathrm{kk}, \mathrm{TR}}$ could be determined at each angular trip location by noting the "transition" from ineffective to effective tripping, here depicted by the dashed line separating the two regimes (see Fig. 7 and Table 1). Critical roughness Reynolds numbers for an isolated roughness element on a blunt body at hypersonic speeds in $\mathrm{CO}_{2}$ were thus found (for $10^{\circ} \leq \phi \leq 30^{\circ}$ ) to be in the range: $\sim 600 \leq \mathrm{Re}_{\mathrm{kk}, \mathrm{TR}} \leq \sim 800$, where $\mathrm{k} / \delta<1$.

Maximum resistance to input disturbances (highest $\mathrm{Re}_{\mathrm{kk}, \mathrm{TR}}$ value) occurred at the upstream-most location $\left(\phi=10^{\circ}\right)$, where the local edge Mach number and momentum thickness Reynolds number were lowest.

\section{B. Air Data}

Figure 8 shows a composite of selected trip thermal wakes and wake centerline axial cuts taken from the air experiments, using the same format as employed in Fig. 6. For trips located at $\phi=20^{\circ}$ and $30^{\circ}$, systematic increases in the roughness Reynolds number resulted in large thermal perturbations in these trip wakes, both in magnitude and in physical extent, consistent with the attainment of effective tripping to turbulence.

Important differences, however, between the air and $\mathrm{CO}_{2}$ results were noted (compare the $\phi=10^{\circ}$ images between Figs. 6 and 8). Subject to the limiting conditions $k / \delta<1$ and $P_{\infty}<0.375$ atm (to avoid ignition of the titanium model), maximum attainable $\operatorname{Re}_{\mathrm{kk}}$ values at $10^{\circ}$ in air were order 1000 , a value insufficient to cause an effective breakdown to turbulence at this location.

Figure 9 and Table 2 summarize the ineffective versus effective tripping results for isolated roughness elements on blunt bodies in hypersonic flight through air as a function of trip location. The dashed line separating these two regimes yielded

$\sim 750 \leq \operatorname{Re}_{\mathrm{kk}, \mathrm{TR}} \leq \sim 850$

for $20^{\circ} \leq \phi \leq 30^{\circ}, \mathrm{k} / \delta<1$.

The line separating these two regimes was extended to $\operatorname{Re}_{\mathbf{k k}}=1000$ at $\phi=10^{\circ}$ as an estimate only. 


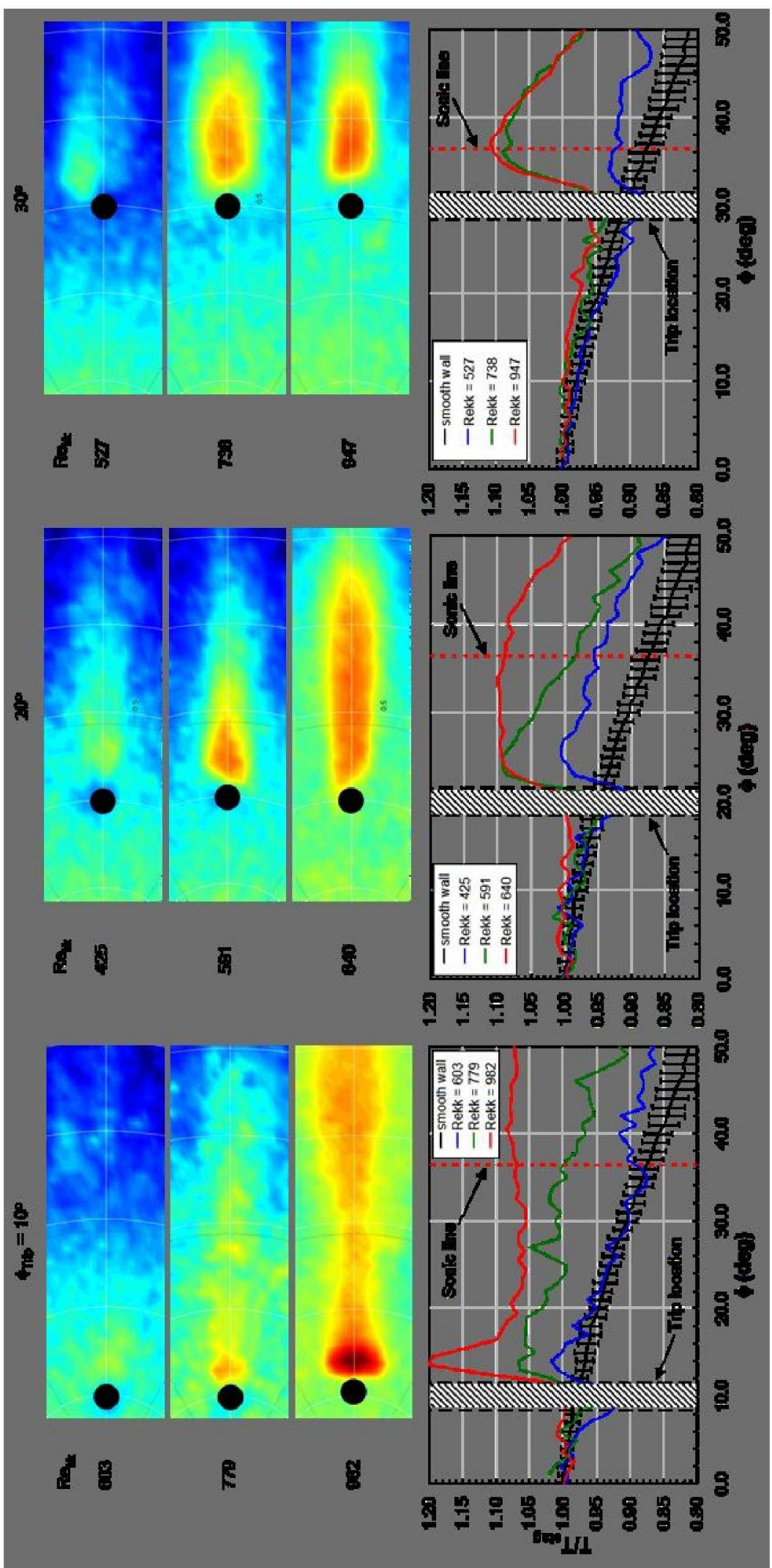

Figure 6. Selected thermal wakes and wake centerline profiles for trips at $\phi=10,20$, and 30 degrees for experiments in $\mathrm{CO}_{2}$. 


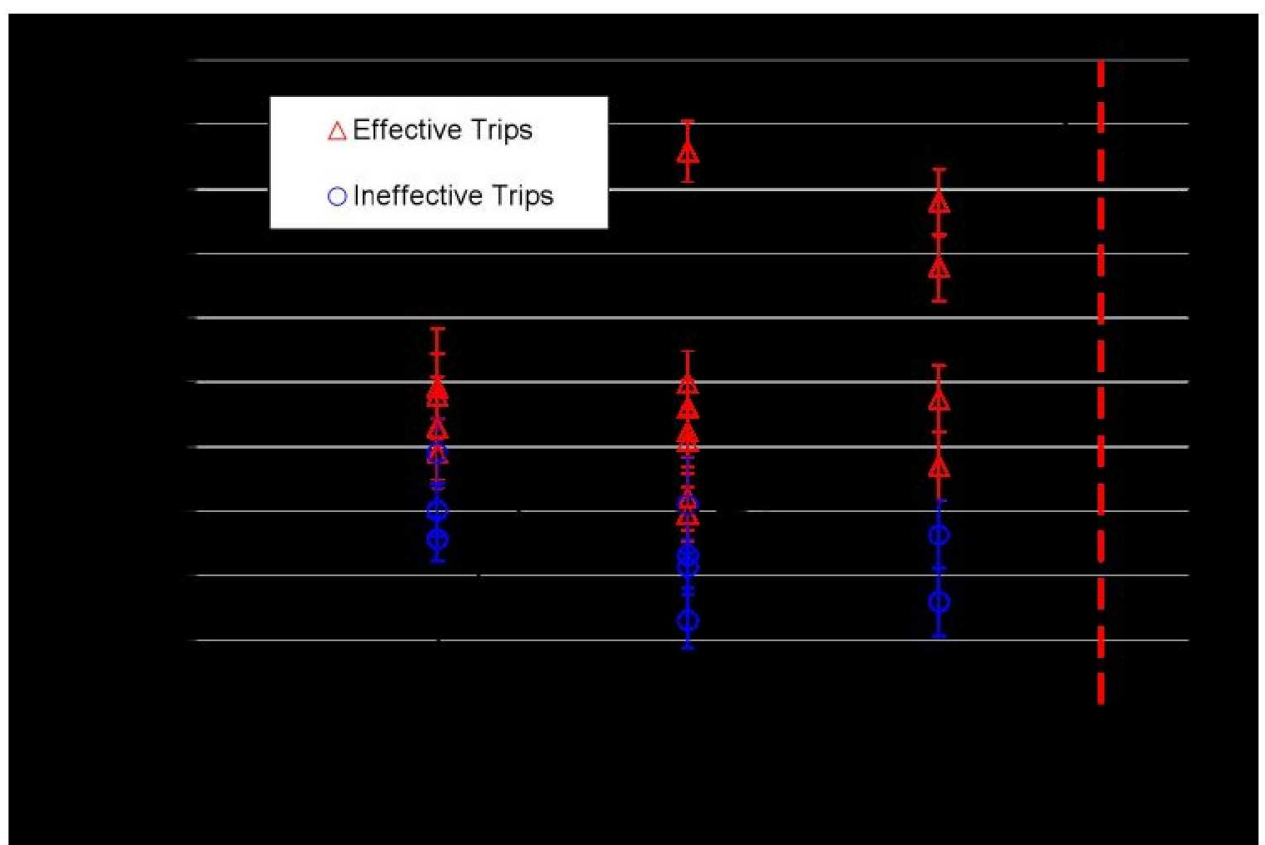

Figure 7. Summary of effective tripping limits for $\mathrm{CO}_{2}$.

\section{Comparison of $\mathrm{CO}_{2}$ and Air Results}

Figure 10 summarizes current and published data bases for the tripping effectiveness of isolated and distributed roughness elements on blunt (hemispherical) bodies in hypersonic free flight. Two principle observations present themselves. First, for isolated roughness elements, it is easier to trip the laminar boundary layer to turbulence for trajectories flown in $\mathrm{CO}_{2}$ versus air, a finding that has consequences for Mars entry missions. Second, as noted earlier in the review paper of Ref. 8, distributed roughness patterns are much more efficient at tripping laminar boundary layers to turbulence than isolated roughness elements. For blunt bodies at hypersonic speeds in air:

$$
\frac{\operatorname{Re}_{\mathrm{kk}, \mathrm{TR}}(\text { isolated })}{\operatorname{Re}_{\mathrm{kk}, \mathrm{TR}}(\text { distributed })} \cong \frac{800}{250} \cong \frac{3}{1}
$$

\section{Conclusions}

1. Critical roughness Reynolds number was found to correlate effective-tripping results for isolated roughness elements immersed within the laminar boundary layer and positioned within the subsonic region of blunt bodies in hypersonic free flight.

2. Critical roughness Reynolds numbers for such isolated roughness elements were found to be higher for flights in air versus $\mathrm{CO}_{2}$ by ratios of $\sim 1.3 / 1$, i.e., for a specified isolated roughness element, it was easier to trip the $\mathrm{CO}_{2}$ boundary layer to turbulence.

3. For both $\mathrm{CO}_{2}$ and air, tripping effectiveness of such isolated roughness elements showed a dependence on location within the subsonic region; tripping was most difficult to achieve for elements positioned closest to the stagnation point, i.e., at low $\mathrm{M}_{\mathrm{e}}$ and $\mathrm{Re}_{\theta}$ conditions.

4. Present air results, compared to transition data for distributed roughness patterns on blunt bodies in hypersonic free flight, showed that distributed roughness patterns are significantly more effective at causing transition to turbulence. Specifically, critical roughness Reynolds numbers for isolated roughness elements were order 3 times larger than corresponding values for distributed roughness patterns. 


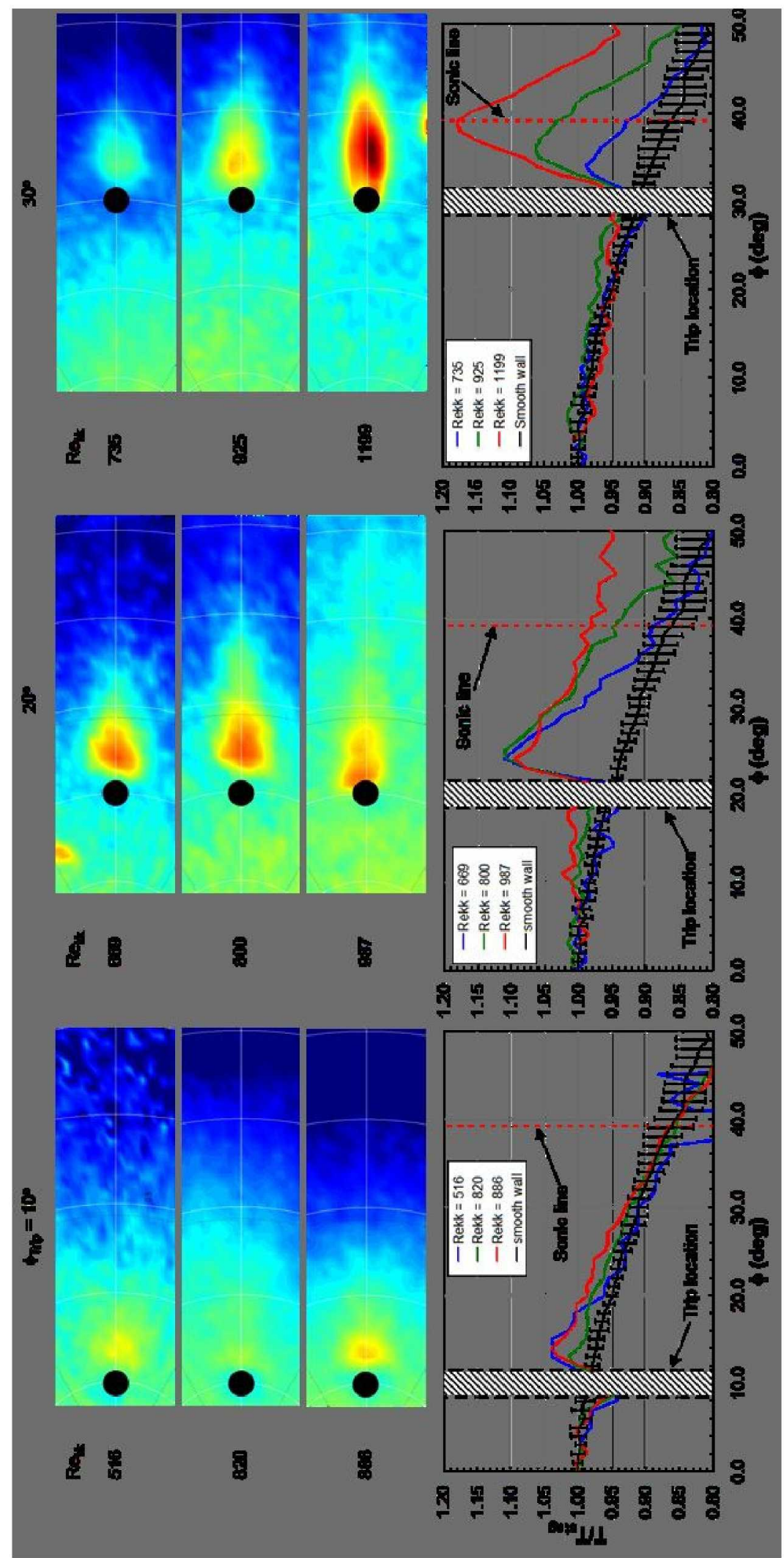

Figure 8. Selected thermal wakes and wake centerline profiles for trips at $\phi=10,20$, and 30 degrees for experiments in air. 


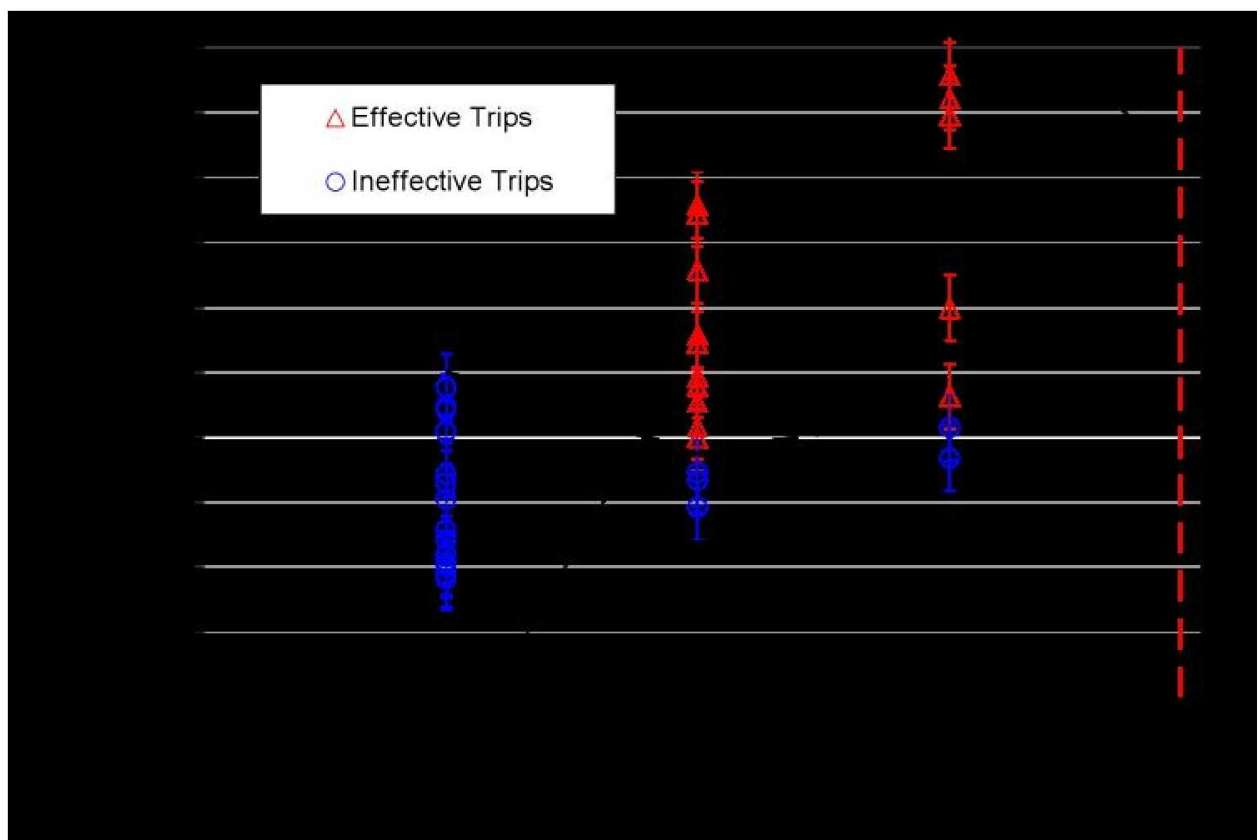

Figure 9. Summary of effective tripping limits for air.

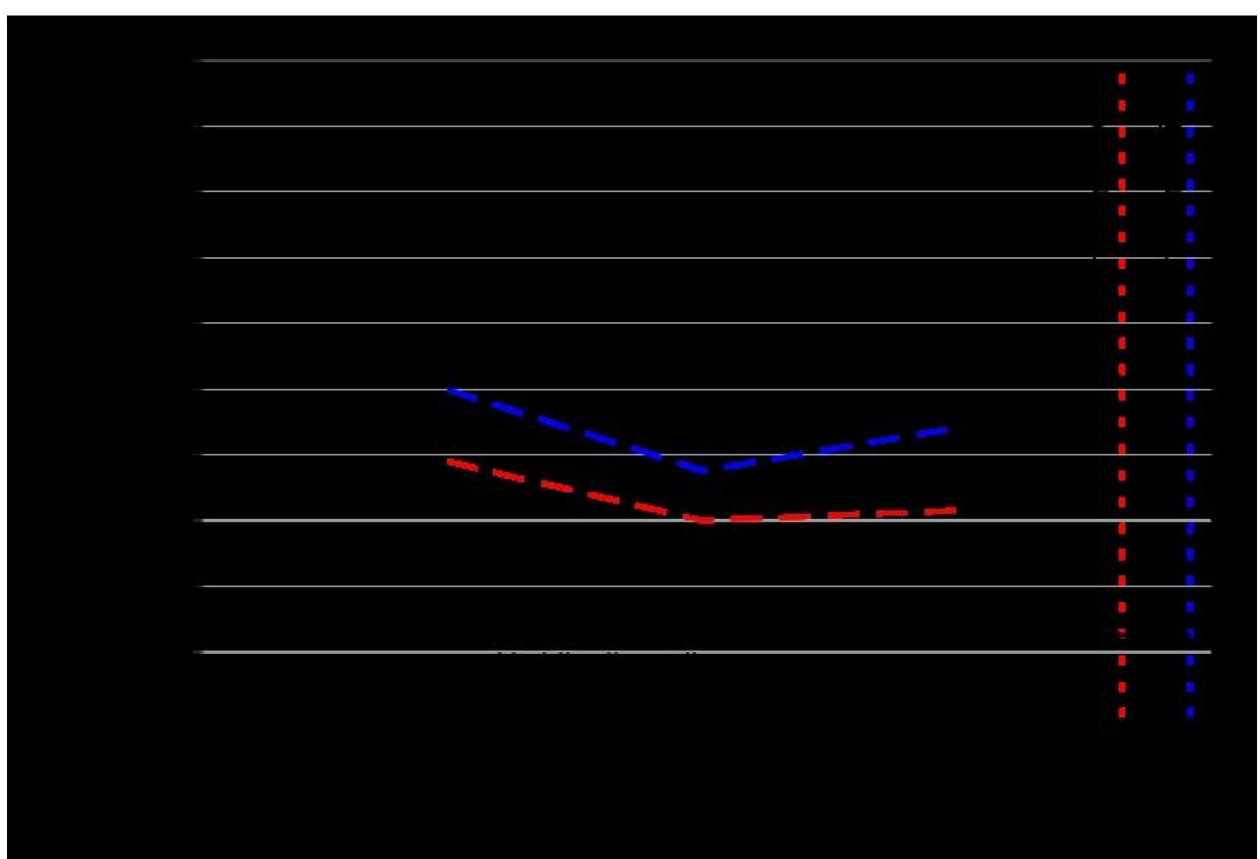

Figure 10. Critical $\mathbf{R e}_{\mathrm{kk}}$ values for isolated and distributed roughness elements on blunt (hemispherical) bodies in hypersonic free flight.

\section{Acknowledgments}

This research was funded by NASA's Fundamental Aeronautics Program, Hypersonics Project. Dinesh Prabhu was supported by Contract NNA04BC25C from NASA Ames Research Center to ELORET Corporation. 


\section{References}

${ }^{1}$ Reda, D. C., "Review and Synthesis of Roughness-Dominated Transition Correlations for Reentry Applications," Journal of Spacecraft and Rockets, Vol. 39, No. 2, March-April 2002, pp. 161-167.

${ }^{2}$ Schiller, L., "Flow in Pipes," Handbook of Experimental Physics, Vol. 4, Pt., 4, Academic Press, Leipzig, Germany, 1932 , pp. 189-192.

${ }^{3}$ Reshotko, E. and Tumin, A., "Role of Transient Growth in Roughness-Induced Transition", AIAA Journal, Vol. 42, No. 4, April 2004, pp. 766-770.

${ }^{4}$ Reda, D.C., Comment on "Role of Transient Growth in Roughness-Induced Transition", AIAA Journal, Vol. 42, No. 4, April 2004, p. 771.

${ }^{5}$ Schneider, S.P., "Laminar-Turbulent Transition on Reentry Capsules and Planetary Probes", Journal of Spacecraft and Rockets, Vol. 43, No. 6, November-December 2006, pp. 1153-1173.

${ }^{6}$ Reshotko, E., "Transition Issues for Atmospheric Entry", Journal of Spacecraft and Rockets, Vol. 45, No. 2, March-April 2008, pp.161-164.

${ }^{7}$ Schneider, S.P. "Effects of Roughness on Hypersonic Boundary-Layer Transition", Journal of Spacecraft and Rockets, Vol. 45, No. 2, March-April 2008, pp. 193-209.

${ }^{8}$ Reda, D.C., Wilder, M.C., Bogdanoff, D.W., and Prabhu, D.K., "Transition Experiments on Blunt Bodies with Distributed Roughness in Hypersonic Free Flight", Journal of Spacecraft and Rockets, Vol. 45, No. 2, March-April 2008, pp. 210-215.

${ }^{9}$ Berry, S.A. and Horvath, T.J. "Discrete-Roughness Transition for Hypersonic Flight Vehicles," Journal of Spacecraft and Rockets, Vol. 45, No. 2, March-April 2008, pp. 216-227.

${ }^{10}$ Amar, A.J., Horvath, T.J., Hollis, B.R., Berger, K.T., Berry, S.A., and Calvert, N., "Protuberance Boundary Layer Transition for Project Orion Crew Entry Vehicle", AIAA 2008-1227, 46 ${ }^{\text {th }}$ Aerospace Sciences Meeting, Reno, NV, January 7-10, 2008.

${ }^{11}$ Berger, K. T., "Aerothermodynamic Testing of the Crew Exploration Vehicle in the LaRC 20-Inch Mach 6 and 31 -Inch Mach 10 Tunnels," AIAA 2008-1225, 46 ${ }^{\text {th }}$ Aerospace Sciences Meeting, Reno, NV, January 7-10, 2008.

${ }^{12}$ Reda, D. C., Wilder, M. C., Bogdanoff, D. W., and Olejniczak, J., “Aerothermodynamic Testing of Ablative Reentry Vehicle Nosetip Materials in Hypersonic Ballistic-Range Environments," AIAA 2004-6829, 1st U.S. Air Force Developmental Test \& Evaluation (DT\&E) Summit, Woodland Hills, CA, November 16-18, 2004.

${ }^{13}$ Wilder, M. C., Reda, D. C., Bogdanoff, D. W., and Prabhu, D. K., "Free-Flight Measurements of Convective Heat Transfer in Hypersonic Ballistic-Range Environments," AIAA 2007-4404, 39th AIAA Thermophysics Conference, Miami, FL, June 25$28,2007$.

${ }^{14}$ Wright, M.J., Candler, G.V., and Bose, D., "Data-Parallel Line Relaxation Method for the Navier-Stokes Equations," $A I A A$ Journal, Vol. 36, No. 9, 1998, pp. 1603-1609. 
Table 1: Summary of data for experiments in $\mathrm{CO}_{2}$.

\begin{tabular}{|c|c|c|c|c|c|c|c|c|c|}
\hline$\phi_{\text {Trip }}$ & $\mathbf{P}_{\infty}(\mathrm{atm})$ & $\begin{array}{c}V_{\infty} \\
(\mathbf{k m} / \mathbf{s})\end{array}$ & $\mathbf{R e}_{\theta}$ & $\mathbf{M}_{\mathbf{e}}$ & $\mathbf{k}(\mu \mathrm{m})$ & k (in) & $\mathbf{k} / \boldsymbol{\delta}$ & $\mathbf{R e}_{\mathbf{k k}}$ & effective? \\
\hline \multirow[t]{9}{*}{10.0} & 0.20 & 3.91 & 13.3 & 0.27 & 15 & 0.0006 & 0.52 & 514 & no \\
\hline & 0.20 & 3.92 & 13.3 & 0.27 & 18 & 0.0007 & 0.60 & 603 & no \\
\hline & 0.20 & 3.91 & 13.3 & 0.27 & 23 & 0.0009 & 0.78 & 779 & no \\
\hline & 0.20 & 3.92 & 13.3 & 0.27 & 23 & 0.0009 & 0.78 & 779 & yes \\
\hline & 0.20 & 3.91 & 13.3 & 0.27 & 23 & 0.0009 & 0.78 & 779 & yes \\
\hline & 0.30 & 3.67 & 15.2 & 0.26 & 18 & 0.0007 & 0.72 & 858 & yes \\
\hline & 0.30 & 3.67 & 15.2 & 0.26 & 18 & 0.0007 & 0.72 & 858 & yes \\
\hline & 0.30 & 3.67 & 15.2 & 0.26 & 20 & 0.0008 & 0.82 & 982 & yes \\
\hline & 0.20 & 3.91 & 13.3 & 0.27 & 28 & 0.0011 & 0.95 & 958 & yes \\
\hline \multirow[t]{16}{*}{20.0} & 0.20 & 3.91 & 45.7 & 0.53 & 5 & 0.0002 & 0.16 & 260 & no \\
\hline & 0.20 & 3.95 & 45.7 & 0.53 & 8 & 0.0003 & 0.24 & 425 & no \\
\hline & 0.22 & 4.00 & 47.2 & 0.53 & 8 & 0.0003 & 0.25 & 462 & no \\
\hline & 0.175 & 3.94 & 43.6 & 0.54 & 10 & 0.0004 & 0.34 & 621 & no \\
\hline & 0.20 & 3.95 & 45.7 & 0.53 & 10 & 0.0004 & 0.32 & 591 & yes \\
\hline & 0.20 & 3.95 & 45.7 & 0.53 & 10 & 0.0004 & 0.32 & 591 & yes \\
\hline & 0.22 & 4.00 & 47.2 & 0.53 & 10 & 0.0004 & 0.33 & 640 & yes \\
\hline & 0.22 & 4.00 & 47.2 & 0.53 & 13 & 0.0005 & 0.42 & 817 & yes \\
\hline & 0.175 & 3.94 & 43.6 & 0.54 & 15 & 0.0006 & 0.46 & 846 & yes \\
\hline & 0.175 & 3.94 & 43.6 & 0.54 & 15 & 0.0006 & 0.46 & 846 & yes \\
\hline & 0.175 & 3.94 & 43.6 & 0.54 & 15 & 0.0006 & 0.46 & 846 & yes \\
\hline & 0.20 & 3.91 & 45.7 & 0.53 & 15 & 0.0006 & 0.49 & 920 & yes \\
\hline & 0.20 & 3.95 & 45.7 & 0.53 & 15 & 0.0006 & 0.49 & 920 & yes \\
\hline & 0.22 & 4.00 & 47.2 & 0.53 & 15 & 0.0006 & 0.50 & 996 & yes \\
\hline & 0.20 & 3.94 & 45.7 & 0.53 & 28 & 0.0011 & 0.89 & 1715 & yes \\
\hline & 0.20 & 3.94 & 45.7 & 0.53 & 28 & 0.0011 & 0.89 & 1715 & yes \\
\hline \multirow[t]{12}{*}{30.0} & 0.20 & 4.10 & 93.0 & 0.81 & 5 & 0.0002 & 0.14 & 317 & no \\
\hline & 0.20 & 4.05 & 93.0 & 0.81 & 8 & 0.0003 & 0.22 & 527 & no \\
\hline & 0.20 & 4.10 & 93.0 & 0.81 & 10 & 0.0004 & 0.29 & 738 & yes \\
\hline & 0.20 & 4.10 & 93.0 & 0.81 & 10 & 0.0004 & 0.29 & 738 & yes \\
\hline & 0.20 & 4.05 & 93.0 & 0.81 & 10 & 0.0004 & 0.29 & 738 & yes \\
\hline & 0.20 & 4.05 & 93.0 & 0.81 & 10 & 0.0004 & 0.29 & 738 & yes \\
\hline & 0.20 & 3.92 & 93.0 & 0.81 & 13 & 0.0005 & 0.36 & 947 & yes \\
\hline & 0.20 & 4.10 & 93.0 & 0.81 & 13 & 0.0005 & 0.36 & 947 & yes \\
\hline & 0.20 & 4.05 & 93.0 & 0.81 & 13 & 0.0005 & 0.36 & 947 & yes \\
\hline & 0.20 & 3.92 & 93.0 & 0.81 & 18 & 0.0007 & 0.50 & 1357 & yes \\
\hline & 0.20 & 3.92 & 93.0 & 0.81 & 20 & 0.0008 & 0.58 & 1559 & yes \\
\hline & 0.20 & 3.92 & 93.0 & 0.81 & 28 & 0.0011 & 0.79 & 2157 & yes \\
\hline
\end{tabular}

12 
Table 2: Summary of data for experiments in air.

\begin{tabular}{|c|c|c|c|c|c|c|c|c|c|}
\hline $\begin{array}{l}\phi_{\text {Trip }} \\
\text { (deg) }\end{array}$ & $\begin{array}{c}\mathbf{P}_{\infty} \\
\text { (atm) }\end{array}$ & $\begin{array}{c}\mathbf{V}_{\infty} \\
(\mathbf{k m} / \mathbf{s})\end{array}$ & $\mathbf{R e}_{\theta}$ & $\mathbf{M}_{\mathbf{e}}$ & $\mathbf{k}(\mu \mathbf{m})$ & k (in) & $\mathbf{k} / \delta$ & $\mathbf{R e}_{\mathbf{k k}}$ & effective? \\
\hline \multirow[t]{18}{*}{10.0} & 0.17 & 4.13 & 8.4 & 0.25 & 25 & 0.0010 & 0.49 & 366 & no \\
\hline & 0.18 & 4.10 & 8.6 & 0.25 & 25 & 0.0010 & 0.50 & 378 & no \\
\hline & 0.17 & 4.13 & 8.4 & 0.25 & 28 & 0.0011 & 0.54 & 401 & no \\
\hline & 0.18 & 4.10 & 8.6 & 0.25 & 28 & 0.0011 & 0.55 & 414 & no \\
\hline & 0.18 & 4.10 & 8.6 & 0.25 & 28 & 0.0011 & 0.55 & 414 & no \\
\hline & 0.20 & 4.00 & 8.9 & 0.25 & 28 & 0.0011 & 0.57 & 439 & no \\
\hline & 0.20 & 4.00 & 8.9 & 0.25 & 28 & 0.0011 & 0.57 & 439 & no \\
\hline & 0.20 & 4.00 & 8.9 & 0.25 & 28 & 0.0011 & 0.57 & 439 & no \\
\hline & 0.18 & 4.10 & 8.6 & 0.25 & 33 & 0.0013 & 0.65 & 486 & no \\
\hline & 0.20 & 4.00 & 8.9 & 0.25 & 33 & 0.0013 & 0.68 & 516 & no \\
\hline & 0.17 & 4.13 & 8.4 & 0.25 & 43 & 0.0017 & 0.83 & 611 & no \\
\hline & 0.15 & 4.29 & 8.1 & 0.25 & 51 & 0.0020 & 0.92 & 660 & no \\
\hline & 0.35 & 3.98 & 11.2 & 0.24 & 25 & 0.0010 & 0.64 & 686 & no \\
\hline & 0.35 & 3.98 & 11.2 & 0.24 & 30 & 0.0012 & 0.76 & 819 & no \\
\hline & 0.35 & 3.98 & 11.2 & 0.24 & 33 & 0.0013 & 0.83 & 886 & no \\
\hline & 0.35 & 3.98 & 11.2 & 0.24 & 33 & 0.0013 & 0.83 & 886 & no \\
\hline & 0.305 & 3.99 & 10.5 & 0.24 & 38 & 0.0015 & 0.90 & 894 & no \\
\hline & 0.305 & 3.99 & 10.5 & 0.24 & 41 & 0.0016 & 0.95 & 953 & no \\
\hline \multirow[t]{15}{*}{20.0} & 0.175 & 4.09 & 27.7 & 0.50 & 25 & 0.0010 & 0.46 & 669 & no \\
\hline & 0.185 & 4.03 & 28.2 & 0.49 & 25 & 0.0010 & 0.47 & 691 & no \\
\hline & 0.175 & 4.09 & 27.7 & 0.50 & 30 & 0.0012 & 0.55 & 800 & yes \\
\hline & 0.21 & 4.06 & 29.6 & 0.49 & 28 & 0.0011 & 0.54 & 833 & yes \\
\hline & 0.21 & 4.06 & 29.6 & 0.49 & 28 & 0.0011 & 0.54 & 833 & yes \\
\hline & 0.21 & 4.06 & 29.6 & 0.49 & 30 & 0.0012 & 0.59 & 907 & yes \\
\hline & 0.21 & 4.06 & 29.6 & 0.49 & 30 & 0.0012 & 0.59 & 907 & yes \\
\hline & 0.185 & 4.03 & 28.2 & 0.49 & 36 & 0.0014 & 0.66 & 958 & yes \\
\hline & 0.185 & 4.03 & 28.2 & 0.49 & 36 & 0.0014 & 0.66 & 958 & yes \\
\hline & 0.35 & 3.81 & 37.1 & 0.49 & 20 & 0.0008 & 0.44 & 987 & yes \\
\hline & 0.185 & 4.03 & 28.2 & 0.49 & 41 & 0.0016 & 0.76 & 1090 & yes \\
\hline & 0.35 & 3.81 & 37.1 & 0.49 & 23 & 0.0009 & 0.49 & 1114 & yes \\
\hline & 0.175 & 4.09 & 27.7 & 0.50 & 51 & 0.0020 & 0.92 & 1314 & yes \\
\hline & 0.35 & 3.81 & 37.1 & 0.49 & 30 & 0.0012 & 0.66 & 1488 & yes \\
\hline & 0.175 & 4.09 & 27.7 & 0.50 & 58 & 0.0023 & 1.06 & 1514 & yes \\
\hline \multirow[t]{12}{*}{30.0} & 0.20 & 4.13 & 59.0 & 0.75 & 20 & 0.0008 & 0.35 & 735 & no \\
\hline & 0.20 & 4.22 & 59.0 & 0.75 & 20 & 0.0008 & 0.35 & 735 & no \\
\hline & 0.20 & 4.22 & 59.0 & 0.75 & 20 & 0.0008 & 0.35 & 735 & no \\
\hline & 0.20 & 4.22 & 59.0 & 0.75 & 23 & 0.0009 & 0.40 & 830 & no \\
\hline & 0.20 & 4.22 & 59.0 & 0.75 & 25 & 0.0010 & 0.44 & 925 & yes \\
\hline & 0.20 & 4.13 & 59.0 & 0.75 & 25 & 0.0010 & 0.44 & 925 & yes \\
\hline & 0.20 & 4.08 & 59.2 & 0.75 & 33 & 0.0013 & 0.57 & 1199 & yes \\
\hline & 0.20 & 4.08 & 59.2 & 0.75 & 33 & 0.0013 & 0.57 & 1199 & yes \\
\hline & 0.25 & 4.01 & 64.7 & 0.74 & 33 & 0.0013 & 0.61 & 1789 & yes \\
\hline & 0.25 & 4.01 & 64.7 & 0.74 & 33 & 0.0013 & 0.61 & 1789 & yes \\
\hline & 0.30 & 3.90 & 70.4 & 0.74 & 28 & 0.0011 & 0.56 & 1844 & yes \\
\hline & 0.20 & 4.08 & 59.2 & 0.75 & 53 & 0.0021 & 0.93 & 1915 & yes \\
\hline
\end{tabular}

13

American Institute of Aeronautics and Astronautics 